\title{
COMPARAÇÃO ENTRE MÉTODOS PARA TESTAR A VIABILIDADE DE PÓLEN DE PESSEGUEIRO ${ }^{1}$
}

\author{
PATRÍCIA MILECH EINHARDT², ELÍSIA RODRIGUES CORREA², MARIA DO CARMO B. RASEIRA4
}

\begin{abstract}
RESUMO - Para o sucesso das hibridações controladas, é importante que o pólen a ser utilizado tenha boa viabilidade ( $>30 \%)$. Os métodos para testá-la podem ser classificados em quatro tipos: 1- uso de corantes; 2-germinação in vitro; 3- germinação in vivo; 4- porcentagem de frutificação efetiva, obtida com a utilização do pólen em teste. No presente trabalho, realizado em agosto de 2004, fez-se uma comparação entre os três primeiros métodos citados acima, utilizando-se de amostras de pólen de pessegueiro, coletadas em 2003, de cinco cultivares: Esmeralda, Eldorado, Granada, Maciel e Vanguarda. O meio de cultura utilizado para a germinação in vitro foi constituído de $10 \mathrm{~g}$ de açúcar cristal e $1 \mathrm{~g}$ de ágar para $100 \mathrm{ml}$ de água destilada. Para a germinação in vivo foram emasculadas e polinizadas, em laboratório, flores de ramos coletados no campo e mantidos em frascos com água. Seguiu-se a metodologia utilizada em microscópio de rotina, com corante diferencial a fim de observar os tubos polínicos no estigma ou pistilo. No método de coloração, foi utilizado carmim como corante. Os resultados da análise de variância mostraram que as diferenças entre cultivares, entre métodos e a interação cultivar e método foram altamente significativas. O método de coloração, usando carmin propiônico como corante, foi significativamente superior à germinação in vivo, em todas as cultivares testadas. A germinação in vitro propiciou resultado estatisticamente igual à germinação in vivo, com exceção das cultivares Esmeralda e Granada, nas quais a germinação in vitro foi superior. Entretanto, a maior diferença entre os dois métodos foi de 10,03\% na cultivar Esmeralda que, embora estatisticamente significativa, na prática, seria aceitável em testes de rotina. Concluiu-se que o teste in vitro é representativo da situação in vivo, enquanto o método de coloração superestimou a porcentagem de pólen viável. Termos para indexação: Teste in vivo, teste in vitro, germinação de pólen.
\end{abstract}

\section{COMPARISON AMONG METHODS FOR TESTING POLLEN VIABILITY}

ABSTRACT - It is important that the pollen used in controlled hibridization has a high germination percentage. There are different ways to test pollen viability: 1 . by staining 2 -in vitro pollen germination; 3 - in vivo germination test; 4 -fruit set, obtained by using the pollen to be tested. In the present work, performed in 2004, a comparison was made among the three first methods above. Pollen samples of five cultivars , Esmeralda, Eldorado, Granada, Maciel and Vanguarda, collected in 2003, were used in the experiment. The culture medium for in vitro germination tests was constituted by $10 \mathrm{~g}$ of sucrose and $1 \mathrm{~g}$ of agar dissolved in $100 \mathrm{ml}$ of distilled water. Twigs with flowers on balloon stage were collected and taken to the laboratory where they were placed in recipients containing water. The procedure used was the one described for light microscopy using differential dye, in order to observe the pollen tubes on the stigma or in the pistil. Propionic carmin was used as a dye for the staining method of pollen viability evaluation. Variance analysis showed differences among cultivars, among methods and a highly significant interaction between cultivar and method. The staining method using propionic carmin as a dye gave higher percentage of viability than in vivo germination for all the tested cultivars. In vitro germination was statistically equal to in vivo germination, except for cultivars Esmeralda and Granada for which gave higher germination percentages. However, the largest differences between the two methods was $10.03 \%$ in cv. Esmeralda, which in spite of being statistically significant, practically would be acceptable for routine tests. It was concluded that in vitro tests using the culture medium is representative of the in vivo situation while the staining procedure was not reliable.

Index terms: In vivo test, in vitro test, pollen germination.

\section{INTRODUÇÃO}

Para assegurar o sucesso nas hibridações controladas, é importante que o pólen a ser utilizado tenha boa viabilidade. Em geral, o pólen colhido de flores em adequado estádio de desenvolvimento e corretamente preparado não necessita de testes de viabilidade. Entretanto, não são raras as situações em que o pólen a ser usado tenha sido colhido em outra região, ou mesmo, fornecido através de intercâmbio com outros países. Por outro lado, devido à não-coincidência de floração, é preciso, muitas vezes, armazenar o pólen colhido em um ano, para ser utilizado no ano seguinte. Neste caso, é recomendável testar a viabilidade do mesmo, antes de sua utilização.

Resultados de pesquisa mostram que a porcentagem de germinação e porcentagem de viabilidade do pólen estão em completa acordância (Bolat e Pirlak, 1999).

Scorza e Sherman (1995) consideram que um bom pólen deve apresentar 50 a 80\% de grãos germinados com tubos bem desenvolvidos. À medida que o pólen envelhece, a porcentagem de germinação e o comprimento dos tubos polínicos decrescem. Ainda que o pólen pareça fraco, a presença de alguns tubos polínicos vigorosos indica que o mesmo ainda é suficientemente bom para assegurar, pelo menos, uma moderada frutificação efetiva, apesar da baixa porcentagem de germinação.
Podem-se agrupar os métodos de testar a viabilidade do pólen em quatro tipos: (1) por meio de corantes; (2) germinação in vitro; (3) germinação in vivo, e (4) porcentagem de frutificação efetiva, obtida com a utilização do pólen em teste (Galetta, 1983).

Scorza e Sherman (1995) citam, como mais usados, o método da gota pendente ou os meios com ágar (King and Hene, 1938; Weuner e Chang, 1981). Ambos são testes in vitro.

Considera-se que o método do corante superestima a porcentagem de germinação do pólen, enquanto o teste in vitro a subestima (Galetta, 1983).

Segundo Stanley e Linskens (1974), nenhum teste de viabilidade é completamente satisfatório, principalmente após o pólen ter sido armazenado, pelas seguintes razões: os testes químicos usam corantes que reagem com constituintes químicos ou estruturas cujas presenças podem não refletir a capacidade de o grão de pólen germinar; amostras de grãos de pólen que germinam bem in vitro, podem não produzir suficiente elongação do tubo polínico para afetar a fertilização. Por outro lado, amostras de pólen que parecem não-viáveis quando testadas in vitro, podem produzir boa porcentagem de sementes in vivo; o pólen armazenado pode germinar diferentemente em amostragens repetidas ou em diferentes meios.

No presente trabalho, as mesmas amostras de pólen foram testadas por três diferentes métodos, procurando-se estabelecer se o

\footnotetext{
${ }^{1}$ (Trabalho 141/2005). Recebido: 16/08/2005. Aceito para publicação: 28/03/2006.

${ }^{2}$ Estudante de graduação em Agronomia, Universidade Federal de Pelotas - Pelotas/RS. patyeinhardt@gmail.com

${ }^{3}$ Estudante de pós-graduação, Universidade Federal de Pelotas

${ }^{4}$ Dr $^{\mathrm{a}}$ Pesquisadora EMBRAPA Clima Temperado-CPACT, Pelotas, RS. bassols@cpact.embrapa.br
} 
método rotineiramente utilizado no laboratório de melhoramento genético da Embrapa Clima Temperado (in vitro) era suficientemente representativo da situação in vivo.

\section{MATERIALEMÉTODOS}

Para a realização do ensaio, foram utilizadas amostras de pólen de pessegueiro de cinco cultivares: Esmeralda, Eldorado, Granada, Maciel e Vanguarda, coletadas de botões florais no estádio de balão, na primavera de 2003, conservados no freezer, em dessecador com sílicagel como substância higroscópica, segundo metodologia descrita por Galetta (1983).

Foram utilizados três métodos para testar a viabilidade do pólen: 1- porcentagem de germinação in vitro; 2- porcentagem de germinação in vivo ; 3 - uso de corante.

1- Para o teste de germinação in vitro, o meio de cultura utilizado constituiu-se de $10 \mathrm{~g}$ de açúcar cristal e $1 \mathrm{~g}$ de ágar para $100 \mathrm{ml}$ de água destilada, a qual foi aquecida para total diluição do ágar. Ainda quente, o meio foi distribuído em lâminas adaptadas com dois anéis de PVC, de $21 \mathrm{~mm}$ de diâmetro e $3 \mathrm{~mm}$ de altura (cada anel correspondeu a uma repetição). O pólen foi polvilhado sobre o meio frio, com um pincel. As lâminas foram colocadas em placas de Petri com fundo coberto por papel umedecido (simulando uma câmara úmida), e levadas para incubação em estufa tipo BOD, com temperatura controlada em torno de $24^{\circ} \mathrm{C}$. Após três horas, foi feita a contagem de grãos de pólen germinados, sendo considerados como germinados aqueles que apresentassem tubo polínico de comprimento igual ou superior ao diâmetro do próprio pólen.

2- Na germinação in vivo, foram coletados ramos com flores em estádio de balão, levados ao laboratório e colocados em frascos de vidro com água. Foi feita a emasculação e a polinização das flores, com pólen da mesma cultivar, coletado no ano de 2003 e armazenado. Após quatro dias da polinização, os pistilos foram colocados em frascos de vidro com fixativo 1:1:8 (formol, ácido acético e álcool etílico) e mantidos em geladeira $\left(5^{\circ} \mathrm{C}\right)$ até o momento da avaliação.

Antes da observação, os pistilos foram retirados do fixativo, lavados em água destilada por três vezes e posteriormente transferidos para solução $8 \mathrm{~N}$ de $\mathrm{NaOH}$, onde permaneceram por um período mínimo de 24 horas, à temperatura ambiente $\left(20^{\circ} \mathrm{C}\right)$, com a finalidade de amolecer os tecidos. Após 24 horas, os pistilos foram lavados novamente por três vezes e colocados em uma solução de hipoclorito de sódio a $20 \%$, durante 10 minutos, com o objetivo de clarear os tecidos. A seguir, passaram por nova lavagem em água destilada e foram colocados em solução de lacmoíde a 1\% (1g de lacmoíde para 100ml de água destilada), por 5 minutos. Retirados desta, foi feita nova lavagem, em água destilada. Para o preparo das lâminas, os pistilos foram colocados sobre as mesmas, acrescentando-se duas gotas de lacmoíde e, após o maceramento, foram observados em microscópio. Foi feita a contagem dos grãos de pólen germinados e não-germinados (descoloridos e sem tubo polínico).

3- Para a observação da porcentagem de pólen viável pelo método de coloração, foi utilizado carmim propiônico $(40 \mathrm{ml}$ de ácido propiônico, $60 \mathrm{ml}$ de água destilada e $1 \mathrm{~g}$ de carmim). O pólen foi polvilhado sobre a lâmina com o corante. Cobriu-se com lamínula e procedeu-se à contagem no microscópio óptico, onde se consideraram viável aqueles que coloriram, e inviável aqueles que não coloriram.

A análise foi efetuada por meio do programa SANEST- Sistema de Análise Estatística para Microcomputadores.

O delineamento estatístico foi completamente casualizado, em arranjo fatorial 5 x 3 , (cinco cultivares e três métodos). Foram utilizadas três repetições, sendo as parcelas constituídas de contagens de 100 grãos de pólen (método do corante e germinação in vitro). Para a germinação in vivo, cada parcela foi constituída de cinco pistilos, contando-se um total de 220 a 408 grãos de pólen por repetição.

\section{RESULTADOS E DISCUSSÕES}

Observa-se pela análise de variância que as diferenças entre cultivares, entre métodos e a interação cultivar e método foram altamente significativas (Tabela 1).

TABELA 1 - Porcentagem de pólen viável de cinco cultivares de pessegueiro.

\begin{tabular}{llll}
\hline & CORANTE & IN VITRO & IN VIVO \\
ESMERALDA & $91,49 \mathrm{AB} \mathrm{a}$ & $72,70 \mathrm{~A} \mathrm{~b}$ & $62,67 \mathrm{~A} \mathrm{c}$ \\
GRANADA & $90,13 \mathrm{AB} \mathrm{a}$ & $69,04 \mathrm{AB} \mathrm{b}$ & $60,04 \mathrm{AB} \mathrm{c}$ \\
MACIEL & $94,17 \mathrm{~A} \mathrm{a}$ & $62,35 \mathrm{BC} \mathrm{b}$ & $59,05 \mathrm{AB} \mathrm{b}$ \\
ELDORADO & $80,53 \mathrm{C} \mathrm{a}$ & $59,67 \mathrm{C} \mathrm{b}$ & $53,34 \mathrm{BC} \mathrm{b}$ \\
VANGUARDA & $87,50 \mathrm{~B} \mathrm{a}$ & $41,32 \mathrm{D} \mathrm{b}$ & $48,33 \mathrm{C} \mathrm{b}$ \\
\hline
\end{tabular}

Média ----------- 57,04

Coeficiente de Variação --- 5,124 \%

Médias seguidas de letras minúsculas iguais, nas linhas, e maiúsculas, nas colunas, não diferem entre si, pelo teste Duncan, a 5\% de probabilidade.

O método de coloração, usando carmin propiônico como corante, foi significativamente superior aos outros dois tipos de teste, para todas as cultivares testadas. Entretanto, segundo DER e ET, em cerejeira, os resultados da viabilidade do pólen diferem conforme o corante utilizado.

Por outro lado, em cebola, pólen testado por carmin acético, como corante, apresentou-se como viável, enquanto em testes in vitro não germinou (Lorenzon e Almeida, 1997)

A germinação in vitro apresentou resultados estatisticamente iguais à germinação in vivo, com exceção das cultivares Esmeralda e Granada, nas quais a germinação in vitro foi superior à germinação in vivo. Tais resultados não eram esperados, entretanto cumpre destacar que, como não foi utilizado corte histológico, mas o maceramento (smear and squash), os grãos de pólen não ficaram todos no mesmo plano, o que pode causar algum erro de contagem nos testes in vivo. Além disso, a maior diferença entre os dois métodos foi de $10,03 \%$ na cultivar Esmeralda, aceitável em testes de rotina.

Segundo Scorza e Sherman (1995), as reações com corantes podem não se correlacionar bem com a germinação in vitro ou com a habilidade de efetuar fertilização, especialmente com pólen armazenado. Os resultados obtidos no presente trabalho confirmam essa afirmativa. Os mesmos autores citam trabalho de Werner e Chang, (1981), no qual, comparando cinco corantes, observaram que apenas o MMT $(2,5$ brometo diphemil tetrazólico) teve correlação positiva com a porcentagem de germinação. No presente trabalho, esse corante não foi testado.

\section{CONCLUSÕES}

Pelos resultados obtidos, pode-se concluir que a utilização da germinação in vitro para testes de viabilidade de pólen de pessegueiro, usando o meio e condições descritas na metodologia, fornece resultados satisfatórios em relação à germinação in vivo e é suficientemente acurada e prática para testes de rotina. A observação baseada na coloração dos grãos de pólen em corante superestima a porcentagem de polens viáveis.

\section{REFERÊNCIAS}

BOLAT, Ý.; PIRLAK, L. An investigation on pollen viability, germination and tube growth in some stone fruits. Turkish Journal of Agriculture Forestry, Ankara, v.23, p.383-388, 1999.

DERIN, K.; SINAN, E.T. Determination of pollen quality: quantity and effect of cross pollination on the fruit set and quality in the pomegranate. Turkish Journal of Agriculture Forestry, Ankara, v.25, p.169-173, 2001. 
GALETTA, G. J. Pollen and Seed Management. In: MOORE, J.N.; JANIK, J. (Ed.). Methods in fruit Breeding. Indiana: Purdne Universitz Press, 1983. p.23-47.

LORENZON, M.C.A.; ALMEIDA, E.C.. Viabilidade e germinação do pólen de linhagens parentais de cebola híbrida. Pesquisa Agropecuária Brasileira, Brasília, v.32, n. 4, p.345-349, 1997.
SCORZA, R.; SHERMAN, W. B. Peaches. In: JANIK J.; MOORE, J.N. (Ed.). Fruit brecding. New York: John \& Sons, 1995. p.325-440.

STANLEY, R.G.; LINSKENS, H. F. Pollen biology biochemistry management. Heidelberg Berlin, 1974. 